\title{
Healthy eating through the eyes of adolescents: A qualitative analysis of messages from the Dietary Guidelines for the Brazilian Population
}

\author{
Alimentação saudável na ótica de \\ adolescentes: uma análise qualitativa \\ das mensagens do Guia Alimentar \\ para a População Brasileira
}

Carolina Martins dos Santos CHAGAS1 (iD) 0000-0002-6715-0834

Raquel Braz Assunção BOTELHO1 (iD) 0000-0002-0369-287X

Natacha TORAL ${ }^{1}$ (D) 0000-0003-0297-2340

A B S T R A C T

\section{Objective}

To evaluate the interpretation by adolescents of messages contained in the Dietary Guidelines for the Brazilian Population.

\section{Methods}

Qualitative study of adolescents distributed across "conversation circles". Each group received messages about healthy eating from the Dietary Guidelines and was instructed to develop materials containing their own interpretation thereof, using appealing wording and format. Content analysis was then used to evaluate these materials.

\footnotetext{
$\overline{1}$ Universidade de Brasília, Faculdade de Ciências da Saúde, Programa de Pós-Graduação em Nutrição Humana. Campus Universitário Darcy Ribeiro, 70910-900. Brasília, DF, Brasil. Correspondência para/Correspondence to: CMS CHAGAS. E-mail: <carolina.nutricionista@gmail.com>.

Support: Fundação de Apoio à Pesquisa do Distrito Federal (Processo nº 0193.000953/2015).

Article based on the thesis by CMS CHAGAS, entitled "Intervenção Nutricional para implementação do Guia Alimentar para a População Brasileira com mobile health entre adolescentes do Distrito Federal”. Universidade de Brasília; 2017.

Como citar este artigo/How to cite this article

Chagas CMS, Botelho RBA, Toral N. Healthy eating through the eyes of adolescents: A qualitative analysis of messages from the Dietary Guidelines for the Brazilian Population. Rev Nutr. 2018;31(6):577-91. http://dx.doi.org/10.1590/1678-98 652018000600007
} 


\section{Results}

Presentation of the produced materials revealed a focus on placing the participants at the center of the process and highlighting the dynamic and innovative nature of each strategy. Corpus analysis identified three clusters of meaning: (I) Food classification and selection model: The participants showed comprehension of the different formulations of foods and their impacts on health, but using other terms. A reductionist understanding of the composition of a healthy diet was observed; (II) Environment and eating practices: the environment was characterized as conducive or not to healthy eating, and open-air markets were recognized as spaces for healthy choices. Creating recipes was judged a wise choice to be shared; and (III) Diet-related individual and collective wellness: consequences of unhealthy food intake were linked to physical and emotional well-being. Concerns were raised about the use of natural resources and the impact of pesticides on individuals and the environment.

\section{Conclusion}

To facilitate understanding of the Dietary Guidelines, the wording of its messages must be adapted, and the discussion about healthy eating and proper diet must be broadened to ascribe greater value to the act of cooking in this population.

Keywords: Adolescent. Food Guide. Healthy Diet. Qualitative Research.

\section{RE S U M O}

\section{Objetivo}

Avaliar a interpretação sobre as mensagens do Guia Alimentar para a População Brasileira na ótica de adolescentes.

\section{Métodos}

Estudo qualitativo com adolescentes distribuídos em rodas de conversa. Cada grupo trabalhou com mensagens sobre alimentação saudável do Guia Alimentar e foram orientados a elaborar materiais contendo a interpretação dos adolescentes, com linguagem e formato atrativos. Realizou-se análise de conteúdo do material.

\section{Resultados}

A apresentação do material enfatizou a necessidade de mostrar o protagonismo dos participantes, a dinamicidade e a inovação criada em cada estratégia. Do corpus, emergiram três núcleos de sentido: (I) Modelo de classificação e escolha dos alimentos: verificou-se compreensão das diferentes formulações dos alimentos e seus impactos na saúde, mas com adoção de outras terminologias. Observou-se entendimento reducionista sobre a composição de uma alimentação saudável; (II) Ambiente e práticas alimentares: o ambiente foi caracterizado como favorável ou não a uma alimentação saudável e feiras livres foram reconhecidas como espaços para escolhas saudáveis. Criar preparações culinárias foi avaliado como uma opção acertada a ser compartilhada; (III) Bem-estar individual e coletivo relacionados à alimentação: consequências do consumo de alimentos não saudáveis foram vinculadas ao bem-estar físico e emocional. Destacaram-se preocupações sobre a utilização dos recursos naturais e agrotóxicos para indivíduos e ambiente.

\section{Conclusão}

Para facilitar o entendimento do Guia Alimentar é necessário adaptar a linguagem das mensagens e ampliar a discussão sobre alimentação saudável e adequada, valorizando o ato de cozinhar nesse grupo.

Palavras-chave: Adolescente. Guias Alimentares. Dieta saudável. Pesquisa Qualitativa.

\section{NTRODUCTION}

Food guides are Food and Nutrition Education (FNE) tools with a focus on promoting healthy lifestyles and preventing diet-related diseases [1-3]. Its structure and content should value ease of understanding, practical applicability, cultural acceptability, and flexibility
[4]. These factors should be considered in all stages of guide construction, as well as during dissemination and implementation of this material, so that it can produce positive health results $[3,5]$.

The Guia Alimentar para a População Brasileira (GAPB, Dietary Guidelines for the 
Brazilian Population) (2014 edition) present information, recommendations, and guidelines on choosing, combining, preparing, and consuming food. They also address environmental factors that facilitate or hinder the adoption of dietary recommendations and propose means of overcoming these challenges. These elements characterize the Dietary Guidelines as a national health promotion strategy and a public policy induction tool [6].

It is well known that the dissemination of information about proper, healthy eating alone has no major impact on the adoption of healthy eating habits [5]. Thus, it is essential to implement innovative educational strategies $[5,7,8]$ that consider the level of literacy, communication, and culture of the target audience [9], and to identify whether the nutritional concepts proposed were fully understood by the public and the expected objectives were achieved.

Several FNE activities have been described in the literature, but the challenge of adapting dietary and nutritional guidelines to achieve effective changes in dietary behavior remains $[8,10,11]$. For young audiences, especially adolescents, educational and motivational strategies to promote health and adequate nutrition are particularly necessary [8]. However, adapting recommendations to encourage effective changes in the eating habits of this population is challenging. Within this context, the present study sought to evaluate the interpretation by adolescents of messages contained in the Dietary Guidelines for the Brazilian Population.

\section{METHODS}

This qualitative study was conducted with adolescents of both sexes, recruited via a convenience sampling strategy from a church, three private schools, and a condominium in the Brazilian Federal District and surrounding areas. Data were collected between May and September 2016. Thirty-two "conversation circles", hereafter referred to as groups, were conducted, with 141 participants. These meetings were led by trained dietitians and had an average duration of 50 minutes. The study was approved by the Research Ethics Committee of the Universidade de Brasilia (UnB, University of Brasilia) School of Health Sciences (protocol n53175015.6.0000.0030).

First, participants sat through a simple oral presentation on the food classification system described in the Dietary Guidelines [6], with images and packaging as visual aids to demonstrate the degrees of food processing (in natura, minimally processed, processed, and ultra-processed) [6]; corn processing was used as the example. Then, adolescents were organized into groups of up to five participants. Each group received a printed message regarding one of the steps outlined in the "Ten Steps to Healthy Diets" section, plus other concepts extracted from the Dietary Guidelines [6]. Each group worked on one message only. No additional explanation was provided by the researchers, nor was any personal content or opinion added. Chart 1 lists the messages presented to each group.

The adolescents were instructed to talk in their group about the principles of a proper, healthy diet described in the message they had received, with the objective of achieving a collective understanding and interpretation of the topics. All steps were worked, except for Step 10 ("Be wary of food advertising and marketing") [6], which was not worked on by any group, due to time constraints. The printed messages were given to the groups at random and repeatedly worked out until topical saturation was achieved.

Then, the groups were asked to prepare materials containing the participants' interpretation of these messages, with a focus on creativity, using wording and a format that would be appealing to adolescents themselves. No specific presentation format was suggested by the investigators. Supplies such as colored pencils, construction paper, figures, food 
Chart 1. Messages and concepts addressed during "conversation circles" with adolescents. Distrito Federal (DF), Brazil, 2016.

Messages
Step 1 (part 1). Make unprocessed or minimally processed foods
the foundation of your diet
Unprocessed or minimally processed foods, when consumed
with variety and largely of vegetable origin, are the foundation
of a nutritionally balanced, flavorful, culturally appropriate diet
and promote a socially and environmentally sustainable food
system.

Step 1 (part 2). Make unprocessed or minimally processed foods the foundation of your diet

Unprocessed or minimally processed foods, when consumed with variety and largely of vegetable origin, are the foundation of a nutritionally balanced, flavorful, culturally appropriate diet and promote a socially and environmentally sustainable food system.

Step 2. Use oils, fats, salt, and sugar sparingly when seasoning and cooking and preparing foods

Oils, fats, salt, and sugar, when used in moderation in culinary preparations that contain unprocessed or minimally processed foods, can diversify one's diet and make it more flavorful without making it nutritionally unbalanced.
Additional concepts

Variety

Concept: no food alone, other than breast milk, gives humans the amount of nutrients their body needs in the proper proportion. Therefore, it is necessary to combine unprocessed foods of vegetable and animal origin (less of the latter). This means: a) A variety of food groups: fruits, nuts, grains, meats, and others; b) Variety within each food group: (1) banana, strawberry, oranges; (2) beans, lentils, chickpeas; (3) rice, potatoes, cassava; (4) meat, fish, eggs.

\section{Culturally appropriate diet}

Concept: a diet that values the eating culture and traditions of the region.

Examples: Rice and pequi in Goiás; cassava meal and acai in the Amazon region; rice and jambu in Pará.

\section{Socially sustainable food system}

Concept: a food production system that promotes social justice, such as: exploitation-free working condition; farmers free to use fertilizers or refrain from using them; equality in work and income opportunities; fair distribution of profits; fewer middlemen.

Environmentally sustainable food system

Concept: a food production system that promotes environmental protection, such as through: use of organic fertilizers; use of nongenetically modified seeds; biological pest and disease control; waste treatment; less distance between growers and consumers; less water and power required for food production.

\section{Moderation}

Concept: oils, fats, salt, and sugar are foods rich in nutrients that can be harmful to health because they increase the risk of heart disease, dental caries, obesity, and other diseases.

*When reducing the amount of salt, it is important to use natural seasonings that enhance flavor instead, including garlic, onion, pepper, parsley, and chives.

Culinary preparations

Concept: culinary preparations are dishes made in home kitchens, cafeterias, or restaurants by mixing unprocessed or minimally processed foods and ingredients (oils, fats, salt, sugar, herbs, vinegar etc.). Examples: rice; beans; fruit juice; stir-fried vegetables; fried eggs; soup; broths; homemade sweets, breads, cakes, and cookies; and homemade pasta (from wheat flour and water alone). 
Chart 1. Messages and concepts addressed during "conversation circles" with adolescents. Distrito Federal (DF), Brazil, 2016.

Messages
Step 3. Limit your intake of processed foods
The ingredients and methods used making processed foods
have a negative effect on their nutritional composition. In small
amounts, they can be consumed as ingredients in culinary
preparations or as a part of meals containing unprocessed or the
minimally processed foods.

Additional concepts

Processed foods and their negatively affected nutritional composition

Concept: although processed foods retain the basic identity and most of the nutrients of the original food (e.g., canned corn), the addition of salt or sugar - usually in very large amounts - turns the end product into a source of nutrients associated with heart disease, obesity, and other diseases.

\section{Processed foods as ingredients in culinary preparations}

Examples: Homemade jerky and beans; eggplant stuffed with canned sardines; a wheat-flour cake with candied fruit in the batter.

Processed foods as a part of meals containing unprocessed or minimally processed foods

Examples: Homemade macaroni with cheese; tomato salad garnished with canned corn.

Step 4 (part 1). Avoid ultra-processed foods

Because of their ingredients, ultra-processed foods are classified as nutritionally unbalanced. Their composition and presentation lead to excessive intake and replacement of unprocessed or minimally processed foods. The way in which they are made, distributed, commercialized, and consumed have negative effects on culture, social life, and the environment.
Ultra-processed foods and their unbalanced composition

Concept: ultra-processed foods are made by large-scale industries. Their manufacturing process involves many stages and many ingredients (salt, sugar, oils, fats, and industrial substances). Some characteristics include: (a) the ingredients of ultra-processed foods are high in fats and/or sugars; (b) they have a high sodium content necessary to extend the product's shelf life, improve its flavor, or hide unpleasant tastes; (c) use of vegetable oils rich in saturated, hydrogenated, and trans fats is common; (d) they are poor in fiber, vitamins, and minerals. All of these factors can facilitate development of heart disease, diabetes, and several types of cancer.

Ultra-processed foods and excessive intake

- Ultra-processed foods "trick" our body's inner workings so that we take longer to feel full or don't feel full at all after eating them.

- They are "hyperpalatable": with the "aid" of sugars, fats, and salt, ultra-processed foods are engineered specifically to make them extremely tasty and lead to dependence.

- They promote unmindful eating: ultra-processed foods can be eaten anywhere; in the street, while driving, while walking - and don't need plates, knives, forks, or tables. This makes it harder for the body to "record" that calories are being consumed.

- They are supersized: as their ingredients are so cheap, ultraprocessed foods are commonly sold in supersized containers at only a slight price premium over "normal" - sized products. This increases the risk of inadvertent overeating.

- Liquid calories: sodas, juice cocktails, and other ready-todrink beverages lead to excessive intake because our bodies have a harder time "recording" the calories provided by sugarsweetened beverages. 
Chart 1. Messages and concepts addressed during "conversation circles" with adolescents. Distrito Federal (DF), Brazil, 2016.

Messages
Step 4 (part 2). Avoid ultra-processed foods
Because of their ingredients, ultra-processed foods are classified
as nutritionally unbalanced. Their composition and presentation
lead to excessive intake and replacement of unprocessed or
minimally processed foods. The way in which they are made,
distributed, commercialized, and consumed have negative
effects on culture, social life, and the environment.

Additional concepts

Ultra-processed foods have a negative effect on culture

- The branding, packaging, labels, and content of ultra-processed foods tend to be identical worldwide.

- The best-known brands are promoted by aggressive advertising campaigns, which often include launching hundreds of products to create a false sense of diversity.

- Under the onslaught of these campaigns, indigenous food cultures tend to be seen as uninteresting, especially by youth.

- The consequence is a desire to consume more and more so that people feel they are part of a modern, superior culture.

Ultra-processed foods have a negative effect on social life

- Ultra-processed foods are engineered and packaged so they can be consumed anytime, anywhere, with no need for any preparation. Their use makes food preparation, eating meals at the family table, and sharing food completely unnecessary.

- They are often eaten at random times, in front of a television set or computer, while walking or driving, while on the phone, and in other settings of relative isolation.

- The "social interactions" usually displayed in ads for these products belie this reality.

Ultra-processed foods have a negative effect on the environment

- Piles and piles of ultra-processed food containers and packages are discarded, and many are not biodegradable, thus requiring new spaces and technologies for waste management.

- High demand for sugar, vegetable oils, and other raw materials widely used in manufacturing ultra-processed foods encourages monocultures which are dependent on pesticides, intensive fertilizer use, and massive irrigation, to the detriment of a more diverse agriculture.

- The manufacturing, distribution, and commercialization flows of ultra-processed foods involve long-haul transport, which means massive power consumption and pollution.

- Huge amounts of water are used at each of the many stages of manufacturing ultra-processed foods.

Step 5. Eat regularly and mindfully, in appropriate settings, and, if possible, not alone

\section{Settings that do not encourage unlimited eating}

People tend to eat more than they need when faced with large quantities of food. A good way of avoiding overeating is to help yourself only once or, at least, wait a while before going back for seconds. A second serving often exceeds our actual needs. "snacking" between meals. Eat slowly and enjoy what you're eating; don't engage in another activity. Try to eat in a clean, comfortable, quiet place which does not encourage you to eat unlimited amounts of food. Avoid eating alone if possible; eat with relatives, friends, coworkers, or classmates. Having someone keep you company during meals facilitates regular, mindful eating, goes well with conducive environments, and helps you enjoy what you are eating more. You should also share in the household chores that precede and follow meals.

\section{Household chores that precede and follow meals}

Examples: Making shopping lists; organizing the pantry; setting the menu; peeling, chopping, and dicing; doing the dishes and utensils. All of these chores provide opportunities for interactions with your loved ones.

"Even if you don't have many opportunities to exercise your culinary skills, value the act of cooking and encourage the people around you - particularly the youngest - to cook. 
Chart 1. Messages and concepts addressed during "conversation circles" with adolescents. Distrito Federal (DF), Brazil, 2016.

\begin{tabular}{l} 
Messages \\
\hline Step 6. Shop at markets that offer a varied range of unprocessed \\
or minimally processed foods \\
Try to shop at greengrocers, street markets, farmer's markets, \\
and other places that sell a varied range of unprocessed or \\
minimally processed foods. Prefer seasonal, locally grown \\
produce. Buy organic and ecologically farmed foods whenever \\
you can, preferably from farmers themselves.
\end{tabular}
you can, preferably from farmers themselves.

Step 7. Develop, exercise, and share culinary skills

If you have culinary skills, try to develop them and share them, particularly with children and young people, with no regard for gender. If you lack culinary skills, try to acquire them - that goes for men and women. To do so, talk to people who know how to cook. Ask your family, friends, coworkers, and schoolmates for recipes. Read cookbooks. Go online. Take classes, perhaps.. but get cooking!

Step 8. Manage time well to give eating the space it deserves

Plan ahead for grocery shopping, keep your pantry organized, and make meal plans or menus for the whole week in advance. Share responsibility for all meal-related household chores with the other members of your family. Make food preparation, and the act of eating itself, special times for being together and enjoying things. Reassess your use of time and identify which activities could be rearranged to make room for mindful eating.

Step 9. When eating out, prefer establishments that serve meals cooked to order

When eating out every day, try to patronize establishments that serve fairly priced meals, cooked to order. Pay-what-you-weigh restaurants can be a good choice, as well as cafeterias that serve home-style cooking at school or at work. Avoid fast-food chains.

\section{Fast-food chains}

The Golden Rule: Always prefer unprocessed or minimally processed foods and culinary preparations over ultra-processed foods.
Concept: Fast-food restaurants are particularly inappropriate places to eat. In addition to offering few or no unprocessed or minimally processed food options, they are often noisy, uncomfortable places which lead patrons to eat too fast and too much.

Additional concepts

Concept: Fruits and vegetables are sold practically year-round throughout the country. However, locally or regionally grown produce that is in season is cheaper, better, and tastier.

\section{Organic and ecologically farmed foods}

Concept: These are foods of vegetable or animal origin that were grown through the sustainable use of natural resources, are free of contaminants, protect biodiversity, contribute to the fair distribution of fertile land, help create jobs, and simultaneously respect and perfect traditional wisdom and foodways.

Culinary skills

Fresh foods usually need to be selected, pre-prepared, seasoned, cooked, combined with other foods, and presented in the form of a dish before they can be eaten. This takes culinary skills! These skills are developed in every society and perfected and passed down over generations. People who have culinary skills make culinary preparations which taste, smell, feel, and look better. This is essential in determining whether people will enjoy their meals more or less.

\section{Meal-related household chores}

Examples: Making shopping lists; organizing the pantry; setting the menu; peeling, chopping, and dicing; doing the dishes and utensils. All of these chores provide opportunities for interactions with your loved ones.

\section{Pay-what-you-weigh (or pay-per-pound) restaurants} wide, varied range of freshly prepared foods and are usually your best bet when eating out every day.

- Choose water, milk, and fruit over soda, dairy beverages, and cookies.

- Never choose ready-made food (e.g., instant "soup", instant "noodles", TV dinners and frozen meals, luncheon and deli meats) over meals cooked to order (e.g., soups, broths, salads, sauces, rice and beans).

- Choose homemade desserts over industrialized sweets.
Concept: Buffet-style restaurants that charge by weight offer a 
packaging, balloons, toys, and party favors were made available to the participants. Each group then presented its work to the other participants and to the investigators. No interruptions, comments, or criticism were allowed during or after the presentations.

For data analysis, the developed materials were photographed, and all discussions were digitally recorded. The conversations were transcribed, and content analysis [12] was performed, consisting of the following steps $[12,13]$ :

(1) Pre-analysis of the material: Comprehensive, in-depth, close reading of the messages produced verbally (oral or written) or figuratively (physical materials), to provide input for the subsequent stages of exploration;

(2) Selection of units of meaning: Units of meaning and sense related to proper and healthy eating through the eyes of adolescents were selected;

(3) Categorization and subcategorization: Excerpts, sentences, or fragments were selected, and the clusters of meaning (agglutinations of similar ideas) that composed the categories and subcategories (when applicable) were identified, as were their respective context units;

(4) Interpretation: degrees of significance were attributed to the analyzed content, in an attempt to understand the determining factors of their characteristics.

The stages listed above were carried out by three raters with experience in the topic and/or audience of the study and in the methodological technique of content analysis. Previous studies of Brazilian adolescents' perceptions of eating and its impact on health [14-19] were used as the theoretical framework.

\section{RE S U L T S}

The participants chose a series of different formats to present their interpretation of the messages contained in the Dietary Guidelines [6]. In $44 \%$ of the groups ( $n=14)$, participants chose to act out sketches or scenarios, using a variety of dramatic resources, such as roleplaying scenes of daily life, interviews, television commercials or shows, and theatrical plays. Another frequent format (37\%; $n=12$ ) was to re-present the material with a new wording, which in most cases was obtained simply by replacing some words in the original messages or reorganizing the original text. Other groups chose to present their messages in musical format $(n=4)$, through photographs $(n=1)$, and even by proposing to shoot a scripted video $(n=1)$. In general, the presentations emphasized a need to show that participants were at the center of the process and highlight the dynamic, innovative nature of the strategies created by the adolescents.

The wording adopted was characterized by absence of formality, the use of ageappropriate slang, errors in semantics and pronunciation, and a lack of knowledge of some terms, such as "minimally processed" and "ultra-processed". Furthermore, the term in natura was understood by adolescents a priori as referring to "unnatural foods".

Construction of a corpus and subsequent analysis of its content pertaining to a proper, healthy diet revealed three clusters of meaning, described below. To preserve the anonymity of the participants, each group was assigned an identifier (G1 through G32) for description of the results.

\section{Food classification and choice of food}

In the participants' reports, it was clear that the food classification scheme was based on explanation of the level of processing used in manufacturing, which determined the nutrient and flavor profile as well as other characteristics related to the quality of the final product. The adolescents' representations of this theme 
suggested an understanding of how the different formulations of foods are associated with their health impacts, in a manner similar to the classification described in the Dietary Guidelines [6]. One exception was an illustration of an ultra-processed yogurt product, which gave rise to uncertainty; it was ultimately considered "an almost healthy food" (G23).

There was substantial adherence to the use of alternative terms to classify foods, such as "natural", "plants", "fresh", and "health food" for in natura foods and "industrialized" for other foodstuffs. Ultra-processed foods were generally expressed as "junk foods" and described as foods containing "[...] fat, sodium, high sugar, and artificial dye" (G6) and "industrial substances" (G10). The context units exemplified in Chart 2 reflect this understanding.

When representing the composition of a healthy diet, the groups were limited to mentioning the intake of fruits and vegetables almost exclusively. The adolescents' discourse highlighted a need to adopt mutually exclusive eating options, that is, what one should and should not eat. Suggested replacements included replacing soft drinks with natural fruit juices, and substituting fried foods and cookies for fruit.

Healthy living in general was tied to narratives that demonstrated different practices

Chart 2. Description of illustrative context units of the cluster of meaning "Food classification and choice of food". Distrito Federal (DF), Brazil, 2016.

\begin{tabular}{|c|c|}
\hline Sub-categories & Context units \\
\hline When referring to foods in natura & $\begin{array}{l}\text { [...] plants or animals, they don't go through any other process (G8). } \\
\text { Natural ones are those obtained directly from plants and animals, and they are healthier } \\
\text { (G10). } \\
\text { Eat fresh food to feel good (G2). }\end{array}$ \\
\hline $\begin{array}{l}\text { When referring to minimally } \\
\text { processed foods }\end{array}$ & $\begin{array}{l}\text { [...] these are foods that have gone through a little processing, which is artificial, before they } \\
\text { arrive at our homes (G12). } \\
\text { I recommend you eat more carrots, broccoli, and some healthier foods, like salad, and even } \\
\text { some semi-industrialized foods (G14). }\end{array}$ \\
\hline When referring to processed foods & $\begin{array}{l}\text { [...] manufactured by the industry with the addition of salt, sugar, and oil, they're not as } \\
\text { healthy (G10). } \\
\text { Processed foods are industrialized foods (G1). }\end{array}$ \\
\hline $\begin{array}{l}\text { When referring to ultra-processed } \\
\text { foods }\end{array}$ & $\begin{array}{l}\text { [...] they go through many manufacturing steps, they are less healthy foods (G10). } \\
\text { This type of industrialized food [frozen lasagna] you eat, a lot of times it's not very healthy } \\
\text { for your body (G14). } \\
\text { I can't believe it, did you buy industrialized stuff [chocolate and packaged snacks] again? } \\
\text { (G15). } \\
\text { If I keep eating this stuff (soda and sandwich cookies) for the rest of my life, I'll end up dying } \\
\text { in the hospital (G22). } \\
\text { Ultra-processed foods are like mega-industrialized foods (G1). }\end{array}$ \\
\hline $\begin{array}{l}\text { Composition of a healthy diet and } \\
\text { healthy eating practices }\end{array}$ & $\begin{array}{l}\text { [...] I'm just going to finish seasoning this super salad that has everything that's green, red, } \\
\text { blue, purple, yellow and everything you're entitled to... with a little salt and pepper, really } \\
\text { natural. So, you won't feel sick again [...] (G14). } \\
\text { You've got to eat corn, papaya, apple, banana (G12). } \\
\text { You've got to eat this (fruit), this is what you should choose. It's got to be this (G15). } \\
\text { Leave it off, leave those potato chips; leave it off, that Nutella }{ }^{\circledR} \text {; leave it off, that sausage } \\
{[\ldots] \text { (G28). }}\end{array}$ \\
\hline
\end{tabular}


not contained in the Dietary Guidelines messages distributed to the groups. These included the importance of engaging physical activity; the adoption of healthy eating habits as a measure to prevent disease or increase longevity; and eating meals at fixed intervals (e.g., every 3 hours). The impact of sedentary lifestyle and diseases caused by an inadequate diet, with very late consequences, were also mentioned.

\section{Environment and eating practices}

In presentations related to the act of eating itself, the adolescents highlighted the eating environment, with some characteristics conducive and others not conducive to a healthy diet. Open-air markets were highlighted as spaces for healthy food choices (Chart 3).
Regarding the act of cooking, a recognition that homemade foods are fresher, tastier, and healthier stood out. In addition, creating and preparing recipes at home, with a suggested terminology of "homemade foods" (G1), was evaluated as a wise choice which should be shared, as it is a special skill.

Two groups addressed the act of cooking with staged role-playing, which included the steps that precede meals (e.g., cutting and seasoning food). However, aspects regarding concentration and pleasure at the time of eating, involvement with meal planning (pantry organization, choosing the menu etc.) and post-meal activities (washing and putting away the dishes etc.) were not mentioned in any presentations, although described in the available material.

Chart 3. Description of illustrative context units of the cluster of meaning "Environment and eating practices". Distrito Federal (DF), Brazil, 2016.

\begin{tabular}{|c|c|}
\hline Sub-categories & Context units \\
\hline $\begin{array}{l}\text { Environment and healthy eating } \\
\text { practices }\end{array}$ & $\begin{array}{l}\text { Have an apple too, with your sister (G2). } \\
{[. . .] \text { it's good to eat at certain times, regular times, in good company, so you'll eat more }} \\
\text { carefully and slowly, which is very important; and in places that won't make you eat more } \\
\text { than you want to (G23). } \\
\text { We must try to avoid frying, [eat] more baked [goods]... an example, instead of fried } \\
\text { chicken, have roast chicken. And instead of salt, we can use natural seasonings, such as } \\
\text { parsley, onion, garlic (G27). } \\
\text { [...] Mrs. Maria started going to an open market near her home, buying healthier foods, and } \\
\text { eating a more balanced diet (G30). }\end{array}$ \\
\hline Unhealthy spaces & $\begin{array}{l}\text { [...] you can have [ultra-processed foods] anytime, anywhere, for example, if you're driving, } \\
\text { you can pick up a snack and eat in your car (G29). } \\
\text { [Ultra-processed foods] can be consumed anywhere, it's faster, people usually pick them } \\
\text { up because it's easier, even though they aren't healthy. [...] they also end up taking away a } \\
\text { custom that was great about Brazilian culture, which was for the whole family to gather and } \\
\text { eat together. They end up pushing the family apart (G32). } \\
\text { Taste much better [...] but won't do me any good (G28). }\end{array}$ \\
\hline The act of cooking & $\begin{array}{l}\text { Rice, when [...] it's fresh... everyone eats a bunch (G7). } \\
\text { We wrote an enigmatic letter to show that cooking is better [...]. Cook, it's better! Choose } \\
\text { healthy foods (G9). } \\
\text { If you know how to cook, use this gift to help (G7). } \\
\text { Yeah, our topic says that if you have cooking skills, cook for everyone, young people and } \\
\text { teenagers, don't keep it to yourself. Share it! (G9). } \\
\text { Having a friend over for lunch... one of them was cooking for the other (G14). }\end{array}$ \\
\hline
\end{tabular}




\section{Diet-related individual and collective wellness}

Participants very emphatically mentioned the harms caused by intake of unhealthy foods, which included aspects related to physical and emotional wellness. Likewise, they also presented the benefits of eating healthy foods (Chart 4).

Concerning the dimensions of sustainability, the participants' narratives mentioned concerns regarding the use of natural resources and the economic and social relations of food production. The use of pesticides was recognized as harmful to health; however, it should be noted that these were mentioned in the context of in natura foods, mistakenly stating that "natural foods" are free from pesticides.

\section{I S C U S S I O N}

The first highlight of this study is the need to adopt more dynamic and illustrative elements about proper, healthy food for dissemination of the Dietary Guideline's messages among adolescents, with a view to their potential leadership role and actual participation. This was observed by the investigators whenever the adolescents played a central role in presentation of the material, bringing the problem and its solution to themselves. This finding is reinforced by prior studies with adolescents suggesting that nutritional interventions should motivate individuals, empower them for action, and incorporate them into the development of educational strategies [14], which should be visually attractive and presented in simple, direct language $[15,16]$.

An understanding of how different formulations of foods are associated with their impacts on health from a persona, individual perspective is another unique contribution of this study, as this way of understanding and classifying foods is a recent concept that stands in stark contrast to the methods previously

Chart 4. Description of illustrative context units of the cluster of meaning "Diet-related individual and collective wellness". Distrito Federal (DF), Brazil, 2016.

\begin{tabular}{|c|c|}
\hline Sub-categories & Context units \\
\hline Physical wellness & $\begin{array}{l}\text { Little food, little food, which made me so fat [...] (G7). } \\
\text { How about you buy some natural juice which is good for your health [...]. And fatty foods, } \\
\text { frozen foods, they're very bad for your health. They can cause high blood pressure (G6). } \\
\text { As he ate it [frozen lasagna], he started to feel sick, so his friend decided to take him to the } \\
\text { hospital. [...] What are you feeling? It hurts right here [stomach], I feel really bad (G14). } \\
\text { [Ultra-processed foods] usually increase your odds of having heart problems, health problems, } \\
\text { because they're harmful (G31). }\end{array}$ \\
\hline Emotional wellness & $\begin{array}{l}\text { If your life's not healthy, you become a sad person [...]. However, if you are a healthy person, } \\
\text { you can be super fashionable, have a super bright life and do exercise. So, you should always } \\
\text { be healthy and be a cheerful, happy person [...] (G16). } \\
\text { Processed foods aren't natural, let's not eat them so we don't feel sick; let's eat natural and } \\
\text { raise our spirits up high (G20). }\end{array}$ \\
\hline $\begin{array}{l}\text { Environmental and social } \\
\text { sustainability }\end{array}$ & $\begin{array}{l}\text { The packaging [of ultra-processed foods] isn't biodegradable, it contaminates the environment, } \\
\text { pollutes it, and takes time to decompose (G29). } \\
\text { Natural foods [...] they're made all-natural, they don't have pesticides or anything like that, } \\
\text { which can hurt the environment as well as ourselves. [On the benefits of in natura foods] } \\
\text { socially it's [...] when we're taking care of the people who are producing our food (G13). } \\
\text { Mrs. Maria [who bought food at the market] helped Mr. John, who was very poor and selling } \\
\text { his produce. Ever since, little Julie has had a balanced diet and Mr. John is now able to make a } \\
\text { profit, buy medicine and things for his house (G30). }\end{array}$ \\
\hline
\end{tabular}


adopted in Brazil and elsewhere in the world. The conventional model of nutrient-based classification allows products with very different characteristics (ingredient mixes) to be grouped into the same category, which can lead to distortions in dietary recommendations and stimulate intake of unhealthy products [20]. Botelho et al. [21] believe the classification of foods according to their degree of processing can be difficult to understand. In these authors' opinion, the formulation of food products is the main aspect to be studied.

Despite the comprehension, alternative terms were used to classify foods as a result of the process encouraged by the investigators so that the adolescents could take ownership of the presented messages and adapt their wording. The difficulties encountered with some words may result from ignorance and/or incorrect application of grammatical rules, as observed for the word in natura, probably because it is a Latin expression and because the prefix "in-" is commonly prepended to words to mean "not" or "without".

At any rate, we may state that the participants understood the presented concepts in their essence (i.e., based on the extent to which foods are processed), despite the adoption of alternative terms. In a similar fashion to the participants of this study, Chilean adults were found to consider yogurt a healthy food in a previous investigation [22]. Perhaps there is a common sense that yogurt is a healthy product. In the absence of legislation to distinguish products by composition, one must pay close attention to product selection because different formulations may be more or less consistent with a healthy diet. It is recommended that natural yogurt be a part of meals and recipes, whereas dairy drinks and yogurt products with added sugar, sweeteners, dyes, and flavorings should be avoided [6].

In the present study, several different terms were commonly attributed to ultra-processed foods, which were sometimes referred to as "junk foods" or "mega-industrialized" products. A similar situation was observed in a qualitative study with 27 adolescents from Rio de Janeiro, in which sweets, soft drinks, and typical fastfood products (hamburger, pizza, and potato chips) were described by the term "junk foods" [17]. Although it is an unhealthy practice that interferes with local food culture, it is important to stress that consumption of these products is commonly associated with this stage of the life course. In addition to being part of their usual diet, "junk foods" are part of the process of forming one's social identity and, often, a factor in peer acceptance in adolescence $[17,23,24]$.

Regarding the understanding of composition and practices involved in a healthy diet, the materials presented by the participants were notable for an absence of other significant dimensions, such as concentration, pleasure, and cultural aspects involved in the act of eating. The composition of a "healthy diet" was reduced almost exclusively to the fruit and vegetable groups, reflecting a greater appreciation of the biological dimension of food to the detriment of other aspects. A similar finding was reported by Silva et al. [17].

Regarding dietary choices, our results indicate the adoption of mutually exclusive practices, although the Dietary Guidelines [6] do not use prohibitive language. For instance, the Guidelines use the verbs "limit" and "avoid" instead of "do not eat". The way in which these "breaks" are expressed may arise from the way in which information on the topic is most commonly disseminated, which generates a strictly biological - common sense of ascribing value to the benefits of certain foods and nutrients and harmful effects to others. Such presentations create categories of what one should or should not eat $[15,25]$.

The present study also suggested that consensuses exist about healthy eating practices, as well as generalizations about "healthy living". The link between a variety of practices (such as engaging in physical activities and eating meals 
at regular intervals) and health was established consensually by the adolescents, without any interference from the material they had received. Prior research on the perceptions of adolescents suggests that this population recognizes that healthy living requires adequate nutrition, physical activity, and formal and informal support for satisfactory maintenance of quality of life; and that excess weight is a risk factor for the long-term development of late-onset chronic diseases [17-19].

Adolescents were able to perceive aspects of the environment associated with healthy eating, as in previous studies [26-29]. Clean, comfortable, quiet environments, without stimuli to encourage excessive eating, make diners eat more attentively and foster "awareness on eating" [30]. Conversely, strong smells, loud noises and sounds, excessive lighting, electronic devices, and other aspects are not conducive to awareness on eating and adherence to healthy eating habits $[31,32]$. The Dietary Guidelines [6] stress these dimensions, with emphasis on the pleasure provided by food, the time and attention devoted to eating, the environment where meals take place, and the sharing of food, all of which reflect the concept of commensality - the social function of eating while emphasizing "how one eats" [33].

As for the factors mentioned by adolescents as barriers to adopting a healthy diet, included in the subcategory "Unhealthy spaces", practicality and the flavor of unhealthy foods stood out, as observed in a previous study by Ensaff et al. [23]. The role of the family was alternatively reported as a facilitator and, at other times, as a barrier to the adoption of healthy eating, again as observed in previous studies $[15,19]$.

Cooking was considered a wise choice that should be shared, despite the remark that the guidelines on moderate use of ingredients and meal planning provided in the Ten Steps to Healthy Diets section of the Guidelines [6] were not fully worked out by the groups, possibly because of their unfamiliarity with culinary practices. On the other hand, Castro et al. [14] noted that educational strategies involving culinary practices for adolescents tend to have positive results. In addition, the act of cooking itself is understood as an educational activity (insofar as it strengthens the process of transmission of culinary skills) and an emancipatory practice (by promoting autonomy and self-care) $[6,34,35]$.

The present study identified that adolescents associate physical wellness with one's dietary habits, emphasizing negative and positive impacts on health. The literature attributes this to a concern about body image $[17,19]$, which is considered an important or very important attribute by most Brazilian adolescents [24].

The novelty of this study lies essentially in how it reveals the process whereby adolescents take ownership of the Guidelines [6], and even suggests terminological choices that are more attuned to the social and cultural context of this population. Another contribution of the study is that ir highlights the need to shift nutritional education strategies from a strictly biological approach to one based on significant learning with a social frame of reference.

One limitation of this study was the lack of investigation of the last point of the Ten Steps to Healthy Diets [6], due to time constraints during the group activity. Furthermore, as in any qualitative study, the extrapolation of results to different age groups and social contexts is limited, especially due to the homogeneity of the sample of this study. Finally, the choice of a convenience sampling strategy inherently limits extrapolation of results.

\section{CONCLUSION}

This study showed that it is essential to consider the central role of adolescents in constructing educational strategies and the need for more dynamic and illustrative materials 
on the topics addressed. It also suggests that adaptations in the wording of messages presented in the Dietary Guidelines may be warranted, as the participants adopted alternative terms to classify foods. In addition, the results point to a need for greater investment in an expanded discussion regarding the understanding of the composition of a healthy diet and the practices involved in healthy eating, especially cooking and its stages, considering the unfamiliarity of adolescents with culinary practices. These factors may facilitate understanding by adolescents and promote the adoption of healthy eating habits.

Future studies should focus on exploring innovative FNE strategies for adolescents, with due consideration to their understanding of what constitutes healthy eating, as well as investigating their understanding of the influence of advertising on dietary practices. Finally, we hope that this study can provide inputs for the design of educational interventions to implement the Dietary Guidelines for the Brazilian Population.

\section{CONTRIBUTORS}

CMS CHAGAS contributed to the conception and design, analysis and interpretation of data, and manuscript writing. RBA BOTELHO contributed to the manuscript writing and review. N TORAL collaborated in the concept and design, analysis and interpretation of data, manuscript writing and review.

\section{REFERENCES}

1. Calderón T, Morón C. La elaboración de guías alimentarias basadas en alimentos en países de América Latina. Food Agric Org. 1999;24:19-28.

2. Martins APB, Levy RB, Claro RM, Moubarac JC, Monteiro CA. Participação crescente de produtos ultraprocessados na dieta brasileira (1987-2009). Rev Saúde Pública. 2013;47(4):656-65. http:// dx.doi.org/10.1590/S0034-8910.2013047004 968

3. Organización de Las Naciones Unidas para la Alimentación y la Agricultura. El estado de las guías alimentarias basadas en alimentos en América Latina y el Caribe: 21 años después de la Conferencia Internacional sobre Nutrición. Roma:
FAO; 2014 [acceso 2017 dez 1]. Disponible en: http://www.fao.org/3/a-i3677s.pdf

4. Barbosa R, Colares L, Soares EA. Desenvolvimento de guias alimentares em diversos países. Rev Nutr. 2008;21(4):455-67. http://dx.doi.org/10.1590/S14 $15-52732008000400010$

5. Contento I. Nutrition education: Linking research, theory and practice. Asia Pac J Clin Nutr. 2008;17(1):176-9.

6. Brasil. Ministério da Saúde. Secretaria de Atenção à Saúde. Guia alimentar para a população brasileira. 2a ed. Brasília: Ministério da Saúde; 2014 [acesso 2017 dez 1]. Disponível em: http://bvsms. saude. gov.br/bvs/publicacoes/guia_alimentar_populacao_ brasileira_2ed.pdf

7. Brasil. Ministério da Saúde. Secretaria de Atenção à Saúde. Política Nacional de alimentação e nutrição. Brasília: Ministério da Saúde; 2012 [acesso 2017 dez 1]. Disponível em: http://bvsms. saude.gov.br/bvs/ publicacoes/politica_nacional_ alimentacao_nutricao.pdf

8. Ramos FP, Santos LAS, Reis ABC. Educação alimentar e nutricional em escolares: uma revisão de literatura. Cad Saúde Pública. 2013;29(11):2147-61. http://dx.doi.org/10.1590/0102-311x00170112

9. World Health Organization. Global strategy on diet, physical activity and health. Paris: WHO; 2004 [cited 2018 Jan 15]. Available from: http:// www.who.int/dietphysicalactivity/strategy/ eb11344/strategy_english_web.pdf

10. Sichieri R, Souza RA. Estratégias para prevenção da obesidade em crianças e adolescentes. Cad Saúde Pública. 2008;24(2):209-23. http://dx.doi. org/10.1590/S0102-311X2008001400002

11. Van Cauwenberghe $E$, Maes L, Spittaels $H$, Van Lenthe FJ, Brug J, Oppert JM, et al. Effectiveness of school-based interventions in Europe to promote healthy nutrition in children and adolescents: Systematic review of published and 'grey' literature. Brit J Nutr. 2010;103(6):781-97. http://dx.doi.org/10.1017/S0007114509993370

12. Bardin L. Análise de conteúdo. Lisboa: Edições 70; 2009.

13. Minayo MCS. O desafio do conhecimento: pesquisa qualitativa em saúde. 9a ed. São Paulo: Hucitec; 2006.

14. Castro IRR, Souza TSN, Maldonado LA, Caniné ES, Rotenberg S, Gugelmin SA. A culinária na promoção da alimentação saudável: delineamento e experimentação de método educativo dirigido a adolescentes e a profissionais das redes de saúde e de educação. Rev Nutr. 2007;20(6):571-88. http:// dx.doi.org/10.1590/S1415-52732007000600001

15. Toral N, Conti MA, Slater B. A alimentação saudável na ótica dos adolescentes: percepções e barreiras à sua implementação e características 
esperadas em materiais educativos. Cad Saúde Pública. 2009;25(11):2386-94. http://dx.doi.org/10. 1590/S0102-311X2009001100009

16. Hingle M, Nichter M, Medeiros M, Grace S. Texting for health: The use of participatory methods to develop healthy lifestyle messages for teens. J Nutr Educ Behav. 2013;45(1):12-19. http://dx.doi. org/10.1016/j.jneb.2012.05.001

17. Silva JG, Teixeira MLO, Ferreira MA. Eating during adolescence and its relations with adolescent health. Texto Contexto Enferm. 2014;23(4):1095-1103. http://dx.doi.org/10.1590/0104-0707201400057 0013

18. Serrano SQ, Vasconcelos MGL, Silva GAP, Cerqueira MMO, Pontes CM. Percepção do adolescente obeso sobre as repercussões da obesidade em sua saúde. Rev Esc Enferm USP. 2010;44(1):25-31. http://dx.doi.org/10.1590/S00 80-62342010000100004

19. Silva DCA, Frazão IS, Osório MM, Vasconcelos MGL. Percepção de adolescentes sobre a prática de alimentação saudável. Ciênc Saúde Coletiva. 2015;20(11):3299-308. http://dx.doi.org/10.15 90/1413-812320152011.00972015

20. Monteiro C, Cannon G, Claro R, Levy RB, Moubarac JC, Martins APB, et al. O sistema alimentar: o grande tema da nutrição: uma nova classificação dos alimentos; implicações para avaliação de dietas, promoção de saúde e bem-estar e prevenção e controle de obesidade e de outras doenças crônicas não transmissíveis. São Paulo: Universidade de São Paulo; 2012 [acesso 2017 dez 1]. Disponível em: http://www.wphna. org/htdocs/downloadsmar2013/journal/The \%20 Food\%20System\%20Portugues.pdf

21. Botelho R, Araújo W, Pineli L. Food formulation and not processing level: Conceptual divergences between public health and food science and technology sectors. Crit Rev Food Sci Nutr. 2016;58(4):1-12. http://dx.doi.org/10.1080/1040 8398.2016.1209159

22. Corvalán C, Reyes M, Garmendia ML, Uauy R. Structural responses to the obesity and noncommunicable diseases epidemic: The Chilean Law of Food Labeling and Advertising. Obes Rev. 2013;14(2):79-87. http://dx.doi.org/10.1111/obr. 12099

23. Ensaff H, Coan S, Sahota P, Braybrook D, Akter H, McLeod H. Adolescents' food choice and the place of plant-based foods. Nutrients. 2015;7(6):4619-37. http://dx.doi.org/10.3390/nu7064619

24. Instituto Brasileiro de Geografia e Estatística. Diretoria de Pesquisas. Coordenação de População e Indicadores Sociais. Pesquisa Nacional de Saúde do Escolar 2015. Rio de Janeiro: IBGE; 2016 [acesso 2017 dez 1]. Disponível em: https://biblioteca. ibge.gov.br/visualizacao/livros/liv97870.pdf
25. Rodrigues EM, Boog MCF. Problematização como estratégia de educação nutricional com adolescentes obesos. Cad Saúde Pública. 2006;22(5):923-31.http://dx.doi.org/10.1590/s0 102-311X20060 00500005

26. Stroebele N, Castro JM. Effect of ambience on food intake and food choice. Nutrition. 2004;20(9):821-38. http://dx.doi.org/10.1016/j.nut.2004.05.012

27. Wansink B, Shimizu M, Cardello AV, Wright AO. Dining in the dark: How uncertainty influences food acceptance in the absence of light. Food Qual Pref. 2012;24(1):209-12. http://dx.doi.org/10.10 16/j.foodqual.2011.09.002

28. Batista MT, Lima ML. Comer o quê com quem? Influência social indirecta no comportamento alimentar ambivalente. Psicol Reflex Crit. 2013;26(1):113-21. http://dx.doi.org/10.1590/S0102-7 9722013000100013

29. Bernhard MC, Peng Li, Allison DB, Gohlke JM. Warm ambient temperature decreases food intake in a simulated office setting: A pilot randomized controlled trial. Front Nutr. 2015;2:20. http://dx. doi.org/10.3389/fnut.2015.00020

30. Robinson E, Aveyard P, Daley A, Jolly K, Lewis A, Lycett $D$, et al. Eating attentively: A systematic review and meta-analysis of the effect of food intake memory and awareness on eating. Am J Clin Nutr. 2013;97(4):728-42. http://dx.doi.org/10. 3945/ajcn.112.045245

31. Jordan CH, Wang W, Donatoni L, Meier BP. Mindful eating: Trait and state mindfulness predict healthier eating behavior. Pers Individ Dif. 2014;68:107-11. http://dx.doi.org/10.1016/J.paid. 2014. 04.013

32. Seguias L, Tapper K. The effect of mindful eating on subsequent intake of a high calorie snack. Appetite. 2017;121:93-100. http://dx.doi.org/10. 1016/j.appet.2017.10.041

33. Moreira SA. Alimentação e comensalidade: aspectos históricos e antropológicos. Ciênc Cult. 2010;62(4):23-6.

34. Brasil. Ministério do Desenvolvimento Social e Combate à Fome. Marco de referência de educação alimentar e nutricional para as políticas públicas. Brasília: Ministério do Desenvolvimento Social; 2012 [acesso 2017 dez 1]. Disponível em: http:// acervodigital.mds.gov.br/xmlui/bitstream/handle/ 123456789/1024/marco_EAN.pdf? sequence=1

35. Castro IRR. Desafios e perspectivas para a promoção da alimentação adequada e saudável no Brasil. Cad Saúde Pública. 2015;31(1):7-9. http:// dx.doi.org/10.1590/0102-311XPE010115

Received: March 16, 2018 Final version: October 10, 2018 Approved: December 3, 2018 